\title{
I'll bet they didn't teach you this at
}
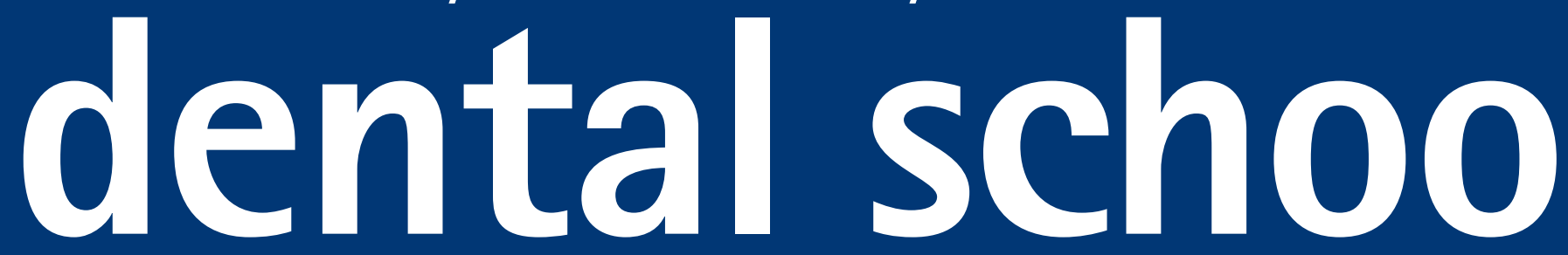

$\mathrm{T}$ hree of the papers in this education and training supplement are directly connected with vocational training (VT), while the fourth touches on the competencies of new graduates in terms of restorative dentistry.

The path to VT has never been especially smooth and recent changes in dentistry in the UK, most specifically the new NHS contract, have arguably not helped this by reducing the potential pool of trainers as more practitioners decrease their NHS commitment or leave it behind completely. Discussions are currently underway to start to solve this difficulty by placing recent graduates in non-NHS practices, and we will report this more fully in the $B D J$ in due course.

It is valuable to remember that the idea, and the subsequent reality, of the VT scheme came from the profession itself and was initially a very modest affair. Growing from an observation that in a complex world of dental care and dental business, it was becoming increasingly unfair to assume that a new graduate had the capacity and competency to immediately be 'let loose' on the public, it was seen as a situation in which both patients and new dentists alike possibly lacked some protection.

Not surprisingly, funding became an issue and the scheme was underwritten by the government through the NHS; completing VT becoming a requirement if a dentist ever wanted to take the role of a principal in an 'NHS' practice. A concept perhaps now viewed as somewhat anachronistic, although still current (for principal, read 'performer'). But as with so much in UK dentistry, the lines between what pertains only to the NHS and what to 'all' dentistry have become increasingly blurred and with a high percentage of young graduates expressing a wish to head ultimately for non-NHS practice, other considerations are urgently needed.

\section{"...the relationship between experienced and inexperienced colleagues is crucial to the continued viability of the former's practices and the latter's all important first years as qualified dentists."}

The current situation aside, the papers in this issue do point to some interesting nuggets of intelligence in relation to the way that practitioners put themselves forward (or not) to become trainers and the way in which both trainers and trainees interact in selecting each other as colleagues. What comes through strongly is that the relationship between experienced and inexperienced colleagues is crucial to the continued viability of the former's practices and the latter's all important first years as qualified dentists.

In many ways the relationship is not so very different from that of the master and apprentice of dentist pre-registration days prior to 1921. The main distinction is that whereas under the apprenticeship system there was little, if any, control over standards of either teaching or the lessons taught, nowadays we expect that both these variables should be as consistent as possible. Herein lays the nub of many of the potential problems and anxieties uncovered by the papers in this issue. For the VDP, the pressure is on to find a friendly and welcoming atmosphere where they will 'feel safe and supported in this new teaching environment.' For the trainer, no lesser pressures are apparent in order to find a VDP who will become a successful member of the team to complement and enhance their practice.

It is not in the least surprising then, to find that experienced trainers often look not for 'high flyers' and those with academic excellence, but for newly qualified dentists with well-rounded personalities and with good social, or people, skills. These are the sort of qualities that a master might well have sought for his potential apprentice a century ago and reflects in a very grassroots way the essence of what good dentistry is about - treating people as people. Perhaps the holistic approach of which we now read so much has ever been with us, we just called it another name.

But if this reflects the objectives of the trainer, what are his or her concerns in relation to providing the trainee with good continuing education and mentoring? It seems that a lack of confidence of being good at teaching or evaluating aspects of training is the primary barrier. As noted above, the need for uniform standards, or as near consensually uniform as possible, is one of the vital differences of today's system and so this is an understandable anxiety expressed by conscientious individuals wanting to do the best for their younger colleagues.

Overall, despite some of the organisational and procedural problems, we should take heart that the system works as well as it might reasonably be expected to. There is a continuing fount of goodwill, common sense and the type of solid, practical experience that enables the forging of that most valuable of assets, the good professional relationship. It is precisely the camaraderie that might produce the type of pragmatism, happily shared and avidly appreciated, which is expressed as, 'I'll bet they didn't teach you this at dental school'. Straightforward sentiments from which good patient care is likely to flow. $\boldsymbol{W}$

\section{Stephen Hancocks OBE Editor-in-Chief}

DOI: 10.1038/bdj.2007.775 